\title{
DECISÕES FINANCEIRAS E O USO DE APLICATIVOS: UM ESTUDO À LUZ DA ECONOMIA COMPORTAMENTAL
}

\author{
FINANCIAL DECISIONS AND THE USE OS APPS: \\ A STUDY FROM THE PERSPECTIVE OS BEHAVIORAL ECONOMICS
}

\author{
KARINA AGATHA MARTIN \\ Universidade Federal do Paraná (UFPR) \\ Doutoranda do PPGDE - UFPR \\ Orcid: https://orcid.org/0000-0003-0666-3908 \\ E-mail: economistakarina@gmail.com \\ Av. Prefeito Lothário Meissner, 632, Curitiba - PR, CEP: 80210-170 \\ ADRIANA SBICCA \\ Universidade Federal do Paraná (UFPR) \\ Professora do Departamento de Economia e do PPGDE - UFPR \\ Orcid: https://orcid.org/0000-0002-6862-9070 \\ E-mail: adsbicca@ufpr.br
}

Submissão: 23/08/2020. Revisão: 27/10/2020. Aceite: 25/02/2021. Publicação: 24/03/2021.

DOI: http://dx.doi.org/10.22277/rgo.v14i2.5443

\begin{abstract}
RESUMO
A Economia Comportamental estuda o processo decisório dos agentes. Ela considera que as características psicológicas e as emoções dos indivíduos, assim como, o modo e o momento em que as opções de escolha são apresentadas podem influenciar as decisões. Seguindo esse arcabouço teórico, intervenções nudges têm sido debatidas no sentido de incentivar melhores resultados em decisões financeiras, com baixo custo e sem restrição da liberdade de escolha. Os aplicativos de gestão financeira procuram estender as facilidades trazidas pela tecnologia e são apontados como uma ferramenta útil para a administração das finanças pessoais. Este artigo parte de um levantamento dos principais desafios presentes nas decisões financeiras sob o ponto de vista da Economia Comportamental. Isso pois, o objetivo do artigo é verificar como os nudges, que têm potencial para auxiliar os usuários a enfrentar esses desafios financeiros, são utilizados por aplicativos de gestão financeira. Destaca-se que, embora nudges tenham sido identificados nos aplicativos, sua utilização é ainda pequena, o que permite concluir que há espaço para a intensificação do seu uso.
\end{abstract}

Palavras-chave: Economia Comportamental. Finanças Pessoais. Aplicativos. Nudge.

Este é um artigo publicado em acesso aberto (Open Access) sob a licença Creative Commons Attribution, que permite uso, distribuição e reprodução em qualquer meio, sem restrições desde que o trabalho original seja corretamente citado. 


\begin{abstract}
Behavioral Economics studies the decision-making process of agents. It considers that the psychological characteristics and emotions of individuals, as well as the way and the moment in which the options of choice are presented can influence decisions. Following this theoretical framework, nudge interventions have been debated to encourage better results in financial decisions, with low cost and without restriction in terms of freedom of choice. Financial management apps aim to extend the facilities brought by technology and are seen as a useful tool for the management of personal finances. This paper starts from a survey of the main challenges present in financial decisions from the point of view of Behavioral Economics. The objective of the article is to verify how nudges, which have the potential to help users face these financial decisions, are used by financial management apps. It is noteworthy that, although nudges have been identified in the apps, their use is still small, which allows us to conclude that there is a space for the intensification of their use.
\end{abstract}

Keywords: Behavioral Finance. Personal Finances. Apps. Nudge.

\title{
1 INTRODUÇÃo
}

Muitos são os desafios enfrentados pelos indivíduos na gestão de suas finanças pessoais seja quanto a organização do orçamento, planos financeiros de curto e longo prazo ou escolha de produtos financeiros. Os dados quanto à poupança, seja para a aposentadoria ou para adquirir bens e serviços, ilustram esse fato. Mais da metade das pessoas que não poupam no Brasil, mais precisamente $64 \%$, demonstraram desejo de começar a fazê-lo no ano subsequente. Porém, parecem não conseguir, pois a evolução dos dados de poupança mostra que estes estão praticamente congelados (ANBIMA, 2019). Mesmo após desejarem poupar, a literatura mostra que muitas vezes há uma incompatibilidade entre o desejo e os comportamentos necessários para que essa poupança seja realizada. São situações em que a questão nem sempre é a falta de renda ou de informação para a realização do objetivo, mas uma incoerência entre metas estabelecidas e decisões financeiras para alcançá-las.

Há uma ampla discussão em torno desse tema envolvendo variadas instituições. A Organização para a Cooperação e Desenvolvimento Econômico (OCDE) tem chamado a atenção para a relevância da "educação financeira". A instituição sustenta a importância da promoção de capacidade financeira, baseada em informação e em instrução financeira adequada com o objetivo de ajudar os indivíduos na administração de suas finanças, no conhecimento de riscos existentes e na prevenção de fraudes (OECD, 2005). Ela também sugere atenção dos governos para políticas, aconselhamento financeiro, regulação específica e para o fornecimento de informações adequadas para promover a capacidade financeira através da gestão das finanças pessoais. Um estudo de Atkinson e Messy (2012) coletou informações de 14 países da OCDE e concluiu que boa parte da população pesquisada possui baixo conhecimento financeiro

Adicionalmente, a diversidade de serviços financeiros e a facilidade de acesso a eles através do uso de tecnologias e ferramentas como os smartphones, estimulam ainda mais o debate. O Mobile Banking, a utilização de dispositivo móvel para efetuar transações financeiras, se difundiu e hoje movimentações financeiras têm migrado dos caixas eletrônicos e do Internet Banking para o Mobile Banking (DELOITTE, 2020). Dentre os fatores que motivam as pessoas a usarem o Mobile Banking há a diversidade de ações possíveis, tais como pagamento, administração de contas, aconselhamento personalizado de investimento, 
Decisões financeiras e o uso de aplicativos:

um estudo à luz da economia comportamental

detecção de fraudes, e ainda maneiras de auxiliar na organização e gestão de finanças. 0 crescimento acentuado tem sido acompanhado pela satisfação do consumidor e pelo uso de dispositivos móveis, apontado como a forma preferida dos brasileiros pagarem contas e realizarem transferências bancárias (DELOITTE, 2020). Dessa forma, na esteira do amplo uso de smartphones e Mobile Banking, os aplicativos de gestão financeira podem ser incorporados pelos indivíduos auxiliando-os no alcance de melhores resultados financeiros.

A Economia Comportamental tem uma ótica complementar à educação financeira. A partir das observações das decisões dos indivíduos no dia a dia, adiciona contribuições da psicologia para explicar as frequentes incoerências entre comportamento e metas financeiras, sustentando que emoções, contexto, características psicológicas e cognitivas são influências importantes na gestão das finanças (TVERSKY; KAHNEMAN, 1974; THALER, 1985; PRELEC; LOEWENSTEIN, 1998; ARIELY; KREISLER, 2019).

Este artigo apresenta como a literatura de Economia Comportamental analisa as decisões de finanças pessoais. $O$ intuito é estabelecer um embasamento teórico para alcançar o objetivo do trabalho: a identificação e análise de nudges utilizados em aplicativos de gestão financeira. O trabalho contribui ao propor um referencial comportamental que subsidia a análise de nudges para gestão de finanças pessoais. Isso pois, há uma diversidade de sugestões disponíveis sobre o assunto, mas que não costumam explicar claramente a maneira como tais "conselhos" se fundamentam em desenvolvimentos da Economia Comportamental. Existem muitas recomendações de autores diversos na internet (a procura por "aplicativos de gestão", "finanças pessoais" em site de busca resulta em mais de 1.000 .000 de respostas) que usualmente descrevem funções de alguns aplicativos denominando-os de "os melhores" que, porém, não apresentam critérios bem estabelecidos e fundamentados para a avaliação. A análise dos aplicativos é outra contribuição deste trabalho que procura preencher uma lacuna na literatura acadêmica que não apresenta pesquisa semelhante.

Assim, a segunda seção deste trabalho expõe três abordagens da Economia Comportamental a respeito das decisões financeiras do cidadão comum. Elas propõem explicar o motivo de muitas vezes os comportamentos não corresponderem a desejos e planos já estabelecidos. Segundo a Economia Comportamental, esta incoerência entre plano e ação se dá principalmente devido à influência no processo decisório das características cognitivas e psicológicas humanas, das emoções e do contexto. Dessa forma, esclarece por que a decisão financeira é desafiadora e é referência para a compreensão de como pequenas "cutucadas" podem resultar em decisões mais benéficas.

A terceira seção aborda as "cutucadas" conhecidas como "nudge". Eles são uma ferramenta, fundamentada na teoria comportamental, que procura conduzir os agentes em suas escolhas para o alcance de melhores resultados. (THALER; SUNSTEIN, 2009). São descritas algumas formas de nudge reconhecidas na literatura que posteriormente serão utilizadas na análise dos aplicativos. A quarta seção trata do método utilizado no estudo e, em seguida, a quinta seção desenvolve a análise dos resultados obtidos. Por fim, as conclusões são apresentadas.

\section{A ÓTICA DA ECONOMIA COMPORTAMENTAL EM RELAÇÃO AOS DESAFIOS DAS DECISÕES FINANCEIRAS}

Segundo Lynch (2011), as decisões financeiras são aquelas explicitamente relacionadas a produtos financeiros ou que afetam dramaticamente o bem-estar financeiro geral do indivíduo. Neste trabalho as decisões financeiras são caracterizadas como desafios, pois 
muitas vezes os agentes desejam, e até mesmo planejam algo, porém, decidem de maneira contrária. Segundo a Economia Comportamental isso ocorre porque as decisões são influenciadas por (i) características cognitivas e psicológicas humanas, (ii) emoções e (iii) o contexto vivido. São estas as três abordagens distintas, porém complementares, que serão apresentadas a seguir.

\subsection{CARACTERÍSTICAS PSICOLÓGICAS HUMANAS}

Autores como Simon (1959), Tversky e Kahneman (1974) e Mullainathan e Thaler (2001), analisam as características psicológicas e cognitivas do ser humano, comparando-as com os pressupostos mais tradicionais da racionalidade maximizadora usualmente sustentados pela Economia. Os autores realçam as limitações humanas que podem explicar comportamentos observados recorrentemente.

Mullainathan e Thaler (2001) destacam duas limitações humanas: a racionalidade limitada e a força de vontade limitada. A racionalidade limitada é um conceito introduzido por Simon (1959) e trabalhado extensamente por ele. Seus elementos fundamentais são limitações: (i) da capacidade cognitiva humana, (ii) na informação disponível ou percebida e (iii) no tempo disponível para a tomada de decisão. Ao considerar estas três características, o autor afirma que o resultado do processo decisório pode não ser ótimo, e tende a ser simplesmente "satisfatório". Isso pois, devido às limitações de tempo, cognição e informação, os indivíduos buscam maneiras de simplificar suas decisões.

Essa abordagem está em linha com desenvolvimentos posteriores que trabalharam em torno da capacidade adaptativa da mente humana e da utilização de atalhos mentais para decidir de maneira mais fácil e rápida, chamados de heurísticas. As heurísticas são regras de bolso ou gatilhos mentais, preestabelecidas a partir de percepções, crenças, preferências e experiência de vida dos indivíduos e que são utilizadas na resolução de problemas com o intuito de simplificá-los (TVERSKY; KAHNEMAN, 1974).

Este processo de simplificação e a utilização de heurísticas podem levar a erros de avaliação e, por conseguinte, aos "vieses". Ou seja, as heurísticas podem gerar resultados viesados em relação ao inicialmente desejado pelo agente. Essa ideia aplicada à análise de decisões financeiras pode auxiliar a compreender os desafios enfrentados pelos agentes e os vieses frequentemente observados. Estes vieses financeiros são muitas vezes previsíveis e sistemáticos, e foram objeto de estudo de vários autores como Benartzi e Thaler (2007) que trataram da dificuldade em decidir para a aposentadoria, da sobrevalorização do benefício presente e subvalorização do futuro (o viés do presente) que pode motivar escolhas impulsivas de consumo, com arrependimento e abandono de planos de longo prazo. Outro exemplo é Meier e Sprenger (2009) que concluíram que o viés do presente está relacionado a existência e magnitude de dívidas no cartão de crédito.

Um processo decisório envolve a escolha de uma opção e o abandono das outras opções restantes. Estas opções renunciadas geram custos de oportunidade, cuja análise é condição para que o agente consiga escolher a alternativa que tem mais valor (utilidade) para ele. Por envolverem valores monetários, as decisões financeiras geram inúmeras possibilidades de como alternativamente gastar tais montantes. Por conseguinte, geram muitos custos de oportunidade tornando a decisão complexa e difícil, o que incentiva os indivíduos a simplificá-la.

Uma das maneiras de simplificar decisões financeiras é através da relatividade (ARIELY; KREISLER, 2019). A relatividade simplifica as decisões por substituir o levantamento dos diversos custos de oportunidade pelo uso de uma referência, que é usada para analisar o valor 
Decisões financeiras e o uso de aplicativos:

um estudo à luz da economia comportamental

de uma opção. Assim, pode-se concluir se o preço é baixo ou alto, se ele está de acordo com o que o produto oferece, e tantas outras análises que os agentes fazem em decisões financeiras comparando esse preço ao de outro produto, por exemplo. A compra de um bem em promoção pode ser decidida pela comparação do preço promocional com o preço sem desconto exposto. O consumidor pode analisar mais o desconto oferecido do que o preço absoluto do produto e os custos de oportunidade envolvidos. Outro exemplo envolvendo a relatividade foi chamado de "efeito conciliatório" e ocorre quando os indivíduos evitam escolher opções extremas (SIMONSON, 1989). Na oferta de bens em três tamanhos pequeno, médio e grande - os agentes utilizam as opções extremas para balizar uma escolha mediana. Assim, a maioria escolhe a opção do meio. As empresas já sabem disso e montam os tamanhos com a intenção de vender mais o tamanho médio. Ambos os exemplos ilustram duas simplificações que os agentes podem fazer durante o processo decisório e que podem conduzi-los a resultados distintos do que inicialmente planejaram, como, por exemplo, compras não desejadas ou em quantidades distintas.

A simplificação da decisão também pode contar com o uso de uma contabilidade mental. Este conceito foi apresentado por Thaler (1985) e refere-se ao processo dos agentes separarem mentalmente o dinheiro em categorias ou contas distintas como alimentação, moradia e transporte. O objetivo pode ser montar um orçamento mental que facilitará as decisões financeiras. A partir desta categorização avalia-se os custos de oportunidade de se consumir um cafezinho, por exemplo, limitados apenas aos itens da conta mental "alimentação". Ou seja, a contabilidade mental pode diminuir o universo de custos de oportunidade envolvidos e, assim, tornar a escolha menos complexa.

O critério de categorização do dinheiro varia e pode depender de como ele foi obtido, de como ele será gasto ou de como os agentes se sentem em relação ao montante. Então, a riqueza pode deixar de ser vista como um todo e o montante de cada categoria, de cada conta mental, pode passar a ter uma tratativa distinta dependendo da categoria em que se aloca determinado valor. Como por exemplo, o 13 salário que pode entrar numa conta mental chamada "Renda Extra", em vez de ser considerado junto à renda anual e, por isso, este montante pode ser gasto de maneira mais leviana, comparado à como é gasta a renda mensal. Outro exemplo ocorre quando os indivíduos possuem dinheiro aplicado que pode ser resgatado, mas eles preferem deixar de pagar o cartão de crédito. Ou seja, o indivíduo respeita de forma exagerada sua conta mental chamada "Poupança" e não transfere parte de seu valor para pagar uma conta que cobra juros altos como a fatura do cartão de crédito (THALER, 1985). Ou seja, a contabilidade mental é utilizada pelas pessoas e ajuda a simplificar as decisões financeiras, o que pode fazer com que o agente tenha uma percepção mais clara do impacto de um gasto no orçamento ao compará-lo com outras despesas da mesma categoria e auxiliar na decisão de gastos. Porém, ela também pode levar a decisões viesadas, como no caso dos exemplos do 13 o salário e da fatura do cartão de crédito vencida.

A força de vontade limitada, assim como a racionalidade limitada, é uma característica humana relevante para se compreender decisões discordantes dos desejos da pessoa e que produz resultados viesados. Ela é relevante em situações em que o indivíduo tem conhecimento de qual é a melhor escolha, porém para realizá-la é necessário que resista a tentações e/ou rejeite seus instintos. Nestes casos, mesmo conhecendo, ou até mesmo planejando o que é melhor para si, o indivíduo pode ter dificuldade em resistir às tentações e acaba por tomar decisões diferentes do que desejava inicialmente. Isso pois, ele tem força de vontade limitada, então consegue se esforçar até certos limites. Como afirmam Mullainathan e Thaler (2001, p. 1096), "a maioria de nós já comeu, bebeu ou gastou muito e se exercitou, 
poupou ou trabalhou pouco". Controlar gastos e poupar são exemplos comuns nos quais a força de vontade limitada pode ser um fator fundamental, pois são necessários autocontrole e planejamento para que o esforço do curto prazo seja estimulado pelos benefícios esperados de longo prazo. Para superar a força de vontade limitada, indivíduos que desejam podem contratar as poupanças forçadas para superar este desafio financeiro Crosgrave (1927) cita os "Clubes de Natal", uma poupança forçada comum nos EUA. Nesta, os participantes pagam boletos durante $o$ ano e acumulam um saldo em uma conta que podem sacar em dezembro e gastar com presentes, férias ou despesas do período. O interessante é que o clube é contratado por decisão do indivíduo que paga uma taxa de administração para participar. Ou seja, o indivíduo paga para conseguir poupar, pois poupar é um desafio diante da sua força de vontade limitada. Efeitos da restrição do acesso ao próprio recurso também foram percebidos por Brune et al. (2011). Os autores relatam um experimento que designou aleatoriamente contas de poupança a pequenos agricultores de Malawi. Uma das contas era convencional e na outra foi acrescentado um compromisso no qual os clientes restringiam seu acesso aos próprios fundos até uma data futura previamente estabelecida. A comparação entre o grupo de controle (sem qualquer conta de poupança aberta pelos pesquisadores) e a conta convencional de poupança não se mostrou estatisticamente significativa. Já a inserção do compromisso apresentou efeitos substanciais e positivos significativos, novamente salientando que a restrição de acesso às próprias finanças tem impacto e pode trazer benefícios financeiros. Assim, algumas características psicológicas humanas como a racionalidade e a força de vontade, ambas limitadas, podem levar os indivíduos a comportamentos distintos do que planejaram. Ambos os conceitos têm sido utilizados como base teórica para justificativas de comportamentos observados relacionados às finanças.

\subsection{A INFLUÊNCIA DAS EMOÇÕES NAS DECISÕES FINANCEIRAS}

Na Teoria dos Prospectos, Kahneman e Tversky (1979) concluem que em decisões sob risco, as pessoas são mais sensíveis à perda do que ao ganho. Assim, a perda é mais dolorosa do que o prazer de um ganho de mesmo montante. Um experimento desenvolvido por Ariely e Shampan'er (2006) é um exemplo ilustrativo. Eles pediram para as pessoas escolherem entre receber gratuitamente um vale presente de $\$ 10$ ou desembolsar $\$ 7$ por um vale presente de \$20. A maioria dos participantes optou pela alternativa gratuita. A evidência experimental mostra que a maioria das pessoas rejeita participar de um jogo com mesmas chances de ganho e perda, a menos que o ganho seja no mínimo o dobro que a perda.

A partir de experimentos, Kahneman e Tversky (1979) observaram que os participantes em uma aposta eram mais propensos ao risco para evitar perdas e menos propensos ao risco para auferir ganhos. Quando solicitado que as pessoas escolhessem entre uma perda certa de $\$ 750$ ou $75 \%$ de chance de perder $\$ 1000$ e $25 \%$ de chance de nada perder; preferiram a segunda opção (87\% das pessoas). Já quando escolheram entre um ganho certo de $\$ 240$ ou $25 \%$ de chance de ganhar $\$ 1000$ e $75 \%$ de chance de nada ganhar, a maioria escolheu a primeira opção ( $84 \%$ das pessoas).

Essa maior sensibilidade às perdas e a maior propensão ao risco quando as escolhas se referem a perdas é a base de uma propriedade sustentada pela Teoria dos Prospectos conhecida como "aversão à perda". Nesta pesquisa duas emoções envolvendo a aversão à perda recebem especial atenção: a dor do pagamento e o viés do presente.

Um pagamento é considerado uma perda, mesmo que se receba em troca um bem ou um serviço, ou seja, mesmo que exista uma contrapartida. Segundo Prelec e Loewenstein (1998), quando os indivíduos fazem compras, muitas vezes sentem uma dor imediata ao pagar, 
Decisões financeiras e o uso de aplicativos:

um estudo à luz da economia comportamental

a "dor do pagamento", que pode diminuir o prazer derivado do consumo. Zellermayer (1996), estudou a dor do pagamento e considerou que esta emoção pode tanto desviar os agentes de seus objetivos, como também pode auxiliá-los a alcançar seus objetivos. Por exemplo, sentir a dor do pagamento pode evitar gastos não planejados. Mazar et al. (2016), apresentam evidências empíricas que a dor do pagamento é mais do que um conceito teórico. Utilizando neuroimagens, os autores observaram que a dor sentida ao simular um pagamento é semelhante a dor afetiva como, por exemplo, a dor causada por se sentir socialmente excluído (diferente da dor física).

Prelec e Loewenstein (1998), perceberam que os indivíduos podem preferir separar o pagamento do consumo. O desacoplamento ocorre quando o consumo e o pagamento acontecem em momentos distintos e esta prática faz com que os indivíduos possam desfrutar plenamente do prazer imediato derivado do consumo sem o desprazer de pagar por ele. Isso explicaria as decisões de pagamento do tipo "all inclusive" ou o pagamento antecipado por férias, mesmo que, talvez, estas opções de pagamento não sejam as melhores do ponto de vista financeiro. Nestes dois casos o pagamento é antecipado, no entanto o desacoplamento também ocorre com a postergação do pagamento, o que acontece ao utilizar um cartão de crédito ou parcelar um pagamento, por exemplo. Soman (2001), através de experimentos, observou que os indivíduos lembram menos do valor gasto quando utilizam cartão de crédito, comparado ao uso de cheques (pagamento à vista) como forma de pagamento. Assim, sem se lembrar ao certo o quanto já gastaram do seu orçamento, podem gastar em demasia nas suas futuras aquisições/contratações, prejudicando suas finanças pessoais. Outros autores também chamam a atenção para o papel da dor do pagamento no controle de gastos. Segundo Ariely e Kreisler (2019), ela tem implicações sobre o autocontrole por deixar as pessoas mais conscientes de suas escolhas. Prelec e Loewenstein (1998), sustentam que ela tem um papel importante na autorregulação do consumidor. A busca pela praticidade no uso dos meios de pagamento modernos (cartão de crédito, débito automático, "Paypall", "Picpay", "compre com um clique") que desacoplam o consumo do pagamento e minimizam a dor do pagamento podem implicar em desafios ainda maiores para os agentes e a gestão de suas finanças pessoais

A sobrevalorização do presente, ou "viés do presente", é comumente lembrada ao tratar de finanças pessoais. No presente, os indivíduos percebem melhor as suas emoções, enquanto as emoções do futuro são, no máximo, uma previsão. Assim, as recompensas imediatas tendem a ser mais valorizadas que recompensas e custos futuros. A aversão à perda pode se relacionar a esta emoção, pois deixar de consumir no presente pode ser percebido como uma perda. Como os indivíduos estão mais conectados com o presente, o prazer do consumo futuro não consegue superar a dor ou a perda de não consumir no presente.

Hershfield, Wimmer e Knutson (2009), estudaram o viés do presente. Utilizaram a ressonância magnética e algumas projeções (fotos) dos participantes representando o "eu atual" e o "eu futuro". As imagens cerebrais comprovaram que a extensão como os indivíduos distinguem entre o "eu atual" e o "eu futuro" prediz sua tendência de desvalorizar os ganhos futuros. Em Hershfield et al. (2011), outro experimento projetava para um grupo de participantes uma fotografia de seus próprios rostos atuais e, para outro grupo, seus rostos na velhice. Depois solicitavam que os participantes escolhessem uma parcela da renda mensal que desejavam poupar para a aposentadoria. Os participantes que viram a projeção de seu "eu futuro" decidiram poupar mais do que o dobro dos que não viram. Segundo os autores, a projeção aumentou a conexão emocional entre os participantes e o seu "eu futuro", o que alterou suas decisões de poupança. 
Assim, pode-se concluir que as emoções influenciam as decisões financeiras dos indivíduos. A aversão à perda sustentada pela Teoria dos Prospectos fundamentou dois conceitos, "dor do pagamento' e o "viés do presente", que têm fortes impactos na análise de decisões financeiras.

\subsection{A PSICOLOGIA DA ESCASSEZ}

Mullainathan e Shafir (2016) definem "escassez" como uma sensação subjetiva de ter mais necessidades do que recursos. Eles analisaram o impacto da escassez nas decisões, não apenas escassez de dinheiro, mas também a escassez de tempo, de amizades (solidão) e de calorias (durante uma dieta).

Os autores identificaram diversas implicações da vivência da escassez como a alteração do foco, por exemplo. Keys et al. (1950), simularam inanição em soldados para estudar suas consequências. Eles perceberam que os participantes passaram a ter fixação por comida, isso pois, em alguns testes em que o assunto era "comida", os participantes famintos se saiam melhor do que os restantes. Segundo os autores, a escassez cria este foco em um nível subconsciente, ela captura a mente e provoca dois efeitos distintos. O primeiro efeito é o aumento do foco, e este pode causar eficiência. Um exemplo ocorre quando o prazo de um projeto está próximo do fim, ou seja, quando se vivencia a escassez de tempo, aumenta-se o foco no projeto, erra-se menos, gera-se mais eficiência. Já o segundo efeito refere-se aos outros elementos da vida que são negligenciados em prol da escassez imediata. Esta negligência ocorre porque a escassez captura a mente o que impacta tanto na capacidade cognitiva, como na habilidade dos indivíduos focarem e mudarem a direção da sua atenção, chamada de "controle executivo".

Mani et al. (2013), organizaram um experimento com agricultores indianos que recebem renda apenas uma vez por ano (sua única fonte de renda é a colheita anual). Assim, o mesmo indivíduo tem a sensação de escassez antes da colheita e a sensação de abundância após a colheita. Eles utilizaram testes diversos para medir a capacidade cognitiva e o controle executivo no mesmo indivíduo antes e após a colheita. Verificaram que após a colheita o mesmo agricultor tinha um desempenho melhor do que antes da colheita. Isso pois, antes da colheita, no período da escassez, eles erravam $25 \%$ e $15 \%$ a mais nos testes de capacidade cognitiva e controle executivo, respectivamente. A mesma pessoa parecia menos inteligente e mais impulsiva quando estava vivendo a escassez. Segundo Mullainathan e Shafir (2016, p. 294), "ser pobre, por exemplo, reduz mais a capacidade cognitiva de uma pessoa do que uma noite inteira sem dormir." E o experimento comprovou que a capacidade cognitiva e o controle executivo em níveis baixos podem não ser uma característica pessoal do indivíduo, mas algo vivido durante um período de escassez. Ou seja, viver uma escassez pode mudar o modo como o indivíduo decide, pode conduzi-lo a resultados diferentes do que desejava.

Shah, Mullainathan e Shafir (2012), observaram através de experimento, que os benefícios dos empréstimos são foco de atenção para atender a escassez financeira imediata, mas os custos destes empréstimos podem ser negligenciados. Ou seja, quando ele vive uma escassez, o indivíduo pode se concentrar apenas na sua necessidade imediata, e assim, não se atentar aos juros ou ainda se terá capacidade financeira futura para quitar esta dívida. Este empréstimo pode ser de dinheiro, mas também de tempo e ambos podem virar uma armadilha devido ao efeito "bola de neve", no qual a dívida cresce de maneira incontrolável.

Assim, Mullainathan e Shafir (2016), sustentam que a escassez ocupa a mente do indivíduo, então pode afetar: (1) o que é importante e é notado por ele; (2) o modo como ele pondera suas escolhas; (3) o modo como ele delibera; (4) o que ele decide; (5) como ele se 
Decisões financeiras e o uso de aplicativos:

um estudo à luz da economia comportamental

controla para manter sua decisão e, (6) consequentemente, como o indivíduo se comporta. Ou seja, viver uma escassez pode alterar as decisões financeiras dos indivíduos.

\section{NUDGE: USANDO AS PROPENSÕES PSICOLÓGICAS EM BENEFÍCIO DOS AGENTES}

A Economia Comportamental tem estudado como as propensões humanas (racionalidade limitada e força de vontade limitada), as emoções (dor do pagamento e viés do presente) e o contexto (escassez) podem influenciar as decisões financeiras dos agentes e procura explicar os motivos dessas decisões, algumas vezes, serem distintas do que eles desejam e planejam. $O$ conhecimento dessas influências pode auxiliar os agentes informandoos sobre os vieses mais frequentes e pode ser a base de propostas em prol dos agentes.

O nudge é uma maneira de guiar os agentes para uma escolha benéfica através de um sutil "empurrão" ou "cutucada" que influencia o processo decisório e auxilia os agentes a fazerem uma escolha de acordo com seus objetivos e planos.

O nudge pode ser uma mudança no contexto ou na maneira de apresentar as opções de escolha ou o problema a ser resolvido. Segundo Thaler e Sunstein (2009), os nudges são intervenções comportamentais soft-paternalistas que não restringem a escolha, são simples e com baixo custo de implementação.

O nudge pode assumir diversas formas como imagens nas embalagens, quadros decorativos, informações pré-escolhidas em formulários, notificações enviadas por aplicativos, design de sites, configurações-padrão de computadores, softwares e smartphones.

A prática de elaborar nudges é chamada de "arquitetura de escolha" e a ferramenta tem sido usada crescentemente por instituições públicas e privadas, pois são intervenções simples, rápidas e baratas. Segundo Ozdemir (2020), atualmente existem mais de 200 "unidades nudge" no mundo, inclusive em governos de vários países como Reino Unido, Estados Unidos, Austrália, Alemanha, Singapura, Holanda.

De acordo com Thaler e Sunstein (2009), os nudges podem ser classificados de acordo com seu formato:

a) nudge padrão: refere-se a uma opção pré-selecionada por um arquiteto de escolha. Ou seja, uma escolha prévia é feita pelo governo ou empresa para o indivíduo, que tem total liberdade para manter esta escolha ou alterá-la facilmente. É interessante observar que uma escolha prévia é inevitável e este padrão pode ser uma escolha benéfica para o agente, aproveitando-se do seu comportamento inercial;

b) nudge enquadramento: ocorre em um processo decisório quando se define um contexto de escolha que conduz o agente a decidir por uma determinada opção. Trata-se de uma apresentação controlada das opções que, por exemplo, pode descrever prejuízos se uma opção não for escolhida provocando a influência da aversão à perda sobre a decisão; ou pode expor as melhores opções nos locais que as pessoas tendem a olhar. Conforme tratado na seção anterior, a maneira como são apresentadas as opções de escolha pode influenciar na decisão do agente;

c) nudge normas sociais: utiliza a vontade natural do ser humano de pertencer e se adequar a grupos para tentar orientar os indivíduos a uma boa escolha. Ou seja, evidencia-se o que os outros cidadãos estão fazendo para incentivar o agente a fazer o mesmo. Leva em consideração que, diante de escolhas complexas, os indivíduos podem se orientar pelo comportamento dos outros agentes. É o chamado "comportamento de manada";

d) nudge da saliência: ocorre quando há ênfase na divulgação de uma informação essencial para a tomada de decisão. Esta informação anteriormente estava obscura devido, por 
exemplo: (1) ao agente não ter se atentado a ela; (2) ao seu cálculo ser complexo; (3) ao se misturar a muitas outras informações. O nudge pode tornar "saliente" esta informação, facilitando e orientando o agente em sua decisão.

Nudges têm sido usados amplamente procurando melhorar as decisões dos indivíduos, inclusive quanto às suas finanças pessoais. O Financial Advice Working Group (2017), a pedido do Tesouro do Reino Unido, definiu 5 regras de bolso para auxiliar os agentes com suas finanças: a) organize suas finanças regularmente; b) gerencie seus empréstimos, não deixe que seus empréstimos gerenciem você, c) economize quando puder - mesmo um pouco ajuda muito, d) economize para sua pensão - é sua renda futura, e) outras pessoas recebem ajuda para aproveitar ao máximo o dinheiro, você também pode. O grupo também chamou a atenção para as características de bons nudges de finanças pessoais, salientando que podem desencadear uma reação emocional (por exemplo, cutucar os novos pais para economizar uma parte do salário para o futuro de seus filhos) ou podem ser baseados em princípios comportamentais (por exemplo, fotos de pessoas envelhecendo pode provocar identificação com o futuro e ajudar nas decisões para a aposentadoria). Chamaram a atenção para que as inovações digitais têm a ferramenta nudge como fundamental para encorajar as pessoas a se engajarem e realizarem poupança e investimentos.

De fato, cada vez mais os indivíduos estão tomando decisões em telas ao fazer uso de websites e dispositivos móveis como celulares. Aplicado a esses ambientes de decisão, o "nudge digital" faz uso do desenho de interface do usuário e através de conteúdo específico, desenho gráfico e textos procura influenciar as escolhas no meio digital. Ele mantém as características básicas do nudge convencional, ou seja, sem restrição de opções de escolha e com intuito de beneficiar o usuário (MIRSCH; LEHRER; JUNG, 2017). No entanto, como é ressaltado pela Economia Comportamental, o ambiente importa para a decisão e os nudges devem ser desenhados adequadamente a depender do ambiente decisório, assim as diretrizes eficazes para o ambiente offline podem ser diferentes do online. Um exemplo já constatado é que o usuário online é mais disposto a divulgar informações, mas mais cauteloso em aceitar opções padrão, o que deve ser levado em consideração pelo nudge digital (SCHNEIDER; WEINMANN; BROCKE, 2018).

Poucos trabalhos estudam a elaboração de nudges de finanças pessoais para aplicativos de celular. Wijland, Hansen e Gardezi (2016), analisaram como insights da Economia Comportamental poderiam melhorar um aplicativo de gestão de finanças pessoais, chamado "YouMoney". Concluíram que os nudges foram importantes para melhorar as decisões financeiras dos estudantes que participaram da pesquisa. Complementarmente, os participantes preferiram características mais básicas do app dirigidas às suas principais preocupações quanto à administração do dinheiro, como poupar, alcançar suas metas e lidar com a sobrevivência no dia a dia.

Stockinger et al. (2015) aplicaram experimentos de laboratório e campo utilizando um protótipo de app chamado "MoneySaver" com objetivo de discutir como os aplicativos de dispositivos móveis podem influenciar decisões. Os autores observaram que os usuários preferem um app que os ajude a poupar e propuseram "cofrinhos" eletrônicos, chamados "piggy-bank", que funcionam como contas da contabilidade mental. Reportaram que mais de 77\% do grupo pesquisado confiou em estratégias usando a contabilidade mental e, diante de uma pergunta se preferiam que seus recursos fossem apresentados em "cofrinhos" separados ou num único, escolheram a primeira opção. A contabilidade mental sugerida pelos "cofrinhos" foi um fator de sucesso que elevou os percentuais de poupança. Quando o aplicativo sugeriu montantes para poupar (como uma opção padrão), houve um impacto na 
Decisões financeiras e o uso de aplicativos:

um estudo à luz da economia comportamental

decisão das pessoas e $50 \%$ decidiu pelo valor sugerido. Como conclusão geral, os autores afirmam que o aplicativo influenciou as decisões de poupança das pessoas e que a Economia Comportamental oferece um conjunto de oportunidades para enriquecer essa influência. $\mathrm{Na}$ próxima seção será detalhada a metodologia utilizada para análise dos aplicativos de celular.

\section{MÉTODO}

Para analisar a incorporação de insights da Economia Comportamental nos aplicativos de celular (apps), foram selecionados alguns apps de gestão financeira. Dentro das lojas de aplicativos, como a "Google Play Store", por exemplo, os apps são categorizados de acordo com a sua função. Na categoria "finanças" encontra-se, entre outros, os aqui chamados "aplicativos de gestão financeira", objeto desta pesquisa. Eles têm o objetivo de auxiliar os usuários na gestão de suas finanças pessoais e, segundo suas próprias descrições, se comprometem a "melhorar suas finanças pessoais", "ajudar você a realizar todos seus objetivos e nunca mais passar por problemas financeiros na vida", "fornecer dicas personalizadas para auxiliar nas escolhas", "alcançar o controle de suas finanças, ganhar visibilidade e ser capaz de tomar decisões importantes e planejar com antecedência", "aumentar sua tranquilidade financeira", entre outras. A amostra foi retirada unicamente da loja "Google Play", pois ela disponibiliza apps para o sistema "Android", utilizado pela grande maioria das marcas de smartphones (STATCOUNTER, 2020). O número de downloads e a "escolha do editor" foram os critérios utilizados para selecionar dez apps para análise. A "escolha do editor" é uma seleção periódica de apps dirigida pela própria empresa Google através da lista chamada "Android Excellence". O Quadro 1 traz algumas informações das características utilizadas para a seleção da amostra de apps. Para não contribuir com ou prejudicar a imagem dos apps da amostra, seus nomes não foram apresentados, sendo chamados por números: app 1, app 2, etc.

Com base nas três abordagens da Economia Comportamental que tratam das decisões de finanças pessoais apresentadas anteriormente, os dez aplicativos selecionados foram analisados com objetivo de identificar a presença de funcionalidades cujos impactos sobre a decisão financeira podem ser compreendidos via insights da Economia Comportamental. Dessa forma, são funcionalidades que podem ser analisadas como ferramentas comportamentais ou nudges.

Quadro 1 - Aplicativos de gestão financeira selecionados

\begin{tabular}{|c|c|c|}
\hline Aplicativo & Número de Downloads & Escolha o editor \\
\hline 1 & 10.000 .000 & Não \\
2 & 10.000 .000 & Não \\
3 & 10.000 .000 & Não \\
4 & 5.000 .000 & Não \\
5 & 5.000 .000 & Não \\
6 & 5.000 .000 & Sim \\
7 & 5.000 .000 & Sim \\
8 & 5.000 .000 & Sim \\
9 & 1.000 .000 & Sim \\
10 & 500.000 & Sim \\
\hline
\end{tabular}

Fonte: elaborado pelas autoras (2020).

\section{ANÁLISE DOS RESULTADOS}

Através da análise dos aplicativos foram identificadas cinco funcionalidades principais: 
1. Implantação e visualização da movimentação financeira;

2. Elaboração de orçamentos;

3. Alerta de vencimentos;

4. Metas de Poupança;

5. Especificação de emoções relacionadas às movimentações financeiras.

A seguir serão apresentadas estas ferramentas, suas conexões com a Economia Comportamental e as influências esperadas sobre as decisões.

\subsection{A VISUALIZAÇÃO E CATEGORIZAÇÃO DA MOVIMENTAÇÃO FINANCEIRA E A ECONOMIA COMPORTAMENTAL}

Esta ferramenta demonstra através de tabelas e gráficos a movimentação financeira dos usuários no período que pode ser semanal, mensal ou anual. A visualização pode ser do valor total movimentado no período ou este valor classificado em categorias como: moradia, educação, alimentação, transporte, etc. A Figura 1 traz uma tela de um dos apps selecionados para ilustrar esta funcionalidade.

A análise dos 10 apps selecionados mostrou que a implantação das entradas e saídas que compõem a movimentação financeira ocorre de três formas distintas e os apps podem adotar apenas uma ou mais:

a) conexão automática do app de gestão financeira com os apps das contas bancárias e de cartões de crédito utilizados pelo usuário. Cada gasto ou recebimento do usuário em conta bancária ou através do cartão de crédito será captado e registrado automaticamente pelo app de gestão financeira;

b) mensagens de SMS (Short Message Service) recebidas pelos usuários em seus smartphones e captadas pelo app de gestão financeira. A cada gasto efetuado, o app do banco ou do cartão de crédito enviará uma mensagem de SMS ao usuário. Ao receber esta mensagem no smartphone, o app de gestão financeira registra a despesa baseado no conteúdo da mensagem que geralmente traz o valor e a razão social do recebedor ou pagador;

c) manualmente, o usuário precisa abrir o app de gestão financeira e registrar a despesa digitando o valor e selecionando a categoria em que a despesa deve ser classificada.

Nas duas primeiras formas de implantação, as entradas e saídas são classificadas automaticamente pelo app em categorias como moradia, educação, renda, etc. $\mathrm{O} a p p$ as classifica baseado no histórico do usuário, na razão social do recebedor, em valores repetidos, etc. e o usuário tem liberdade para revisar esta classificação.

Esta fácil visualização de toda a movimentação financeira do usuário evoca a Economia Comportamental através do nudge da saliência. Isso pois, na maioria dos apps da amostra o saldo disponível é colocado na tela de abertura do app. Torna-se assim a primeira informação disponibilizada e sua facilidade e rapidez pode orientar o usuário em sua decisão, assim como é o propósito do nudge. Um exemplo pode ocorrer quando o usuário abrir o app e verificar que o saldo é mais baixo do que esperava ou mesmo insuficiente para uma compra, de certa maneira o app orienta o usuário a não realizar a compra.

Outro ponto relacionado a Economia Comportamental é a forma de implantação automática da movimentação financeira. Esta possui relação com o nudge padrão. Isso pois, uma vez que o usuário configure o app de gestão financeira para realizar esta tarefa automaticamente, ele não precisa mais tomar decisões em relação a isso. $O$ usuário não 
Decisões financeiras e o uso de aplicativos:

um estudo à luz da economia comportamental

precisa decidir, várias vezes ao dia, se quer implantar ou não cada uma das suas movimentações financeiras. Essa forma de implantação utiliza a inércia do usuário, a opção padrão, para manter o app atualizado o que pode facilitar o uso do aplicativo e a gestão de finanças pessoais do usuário.

Já o registro manual da movimentação financeira, se por um lado pode reduzir a motivação do usuário em usar o aplicativo devido ao esforço requerido para o registro, por outro lado pode evocar a dor do pagamento. Tratando-se de gastos, ter de relembrá-los para registrá-los no app pode fazer com que os usuários sintam a dor do pagamento e isso pode ser útil ou não, dependendo do perfil hedônico do usuário.

Por fim, a visualização dos gastos classificados por categoria também pode ser relacionada à Economia Comportamental. Isso pois, esta visualização pode induzir os usuários a utilizar a Contabilidade Mental e, consequentemente, isso pode influenciar de maneira positiva ou negativa as decisões financeiras. Esta visualização dos gastos categorizados pode auxiliar os usuários na elaboração do orçamento e na limitação dos custos de oportunidade a serem analisados, o que pode induzir os usuários a decisões financeiras melhores ou viesadas a depender de como a gestão da Contabilidade Mental é feita pelo usuário. Este comportamento será discutido com mais detalhes na próxima subseção.

\subsection{ELABORAÇÃO E ACOMPANHAMENTO DE ORÇAMENTOS E A RELAÇÃO COM A CONTABILIDADE MENTAL}

Trata-se de uma ferramenta para criação de um orçamento dentro do app. O usuário estima as despesas, geralmente mensais, que tem com moradia, alimentação, transporte e outros gastos pessoais e então registra manualmente no app. O app repete automaticamente o orçamento de um período para o outro. Para acompanhar o orçamento, o app dispõe os valores orçados e realizados juntos através de tabelas e gráficos. É possível a visualização do saldo total ou dividido por categoria. Na Figura 1 pode-se observar um exemplo de tela contendo um orçamento categorizado e total. $\mathrm{O}$ app também envia alertas (notificações) quando o orçamento de determinada categoria está próximo do fim. 
Figura 1 - Movimentação financeira e orçamento analítico e sintético
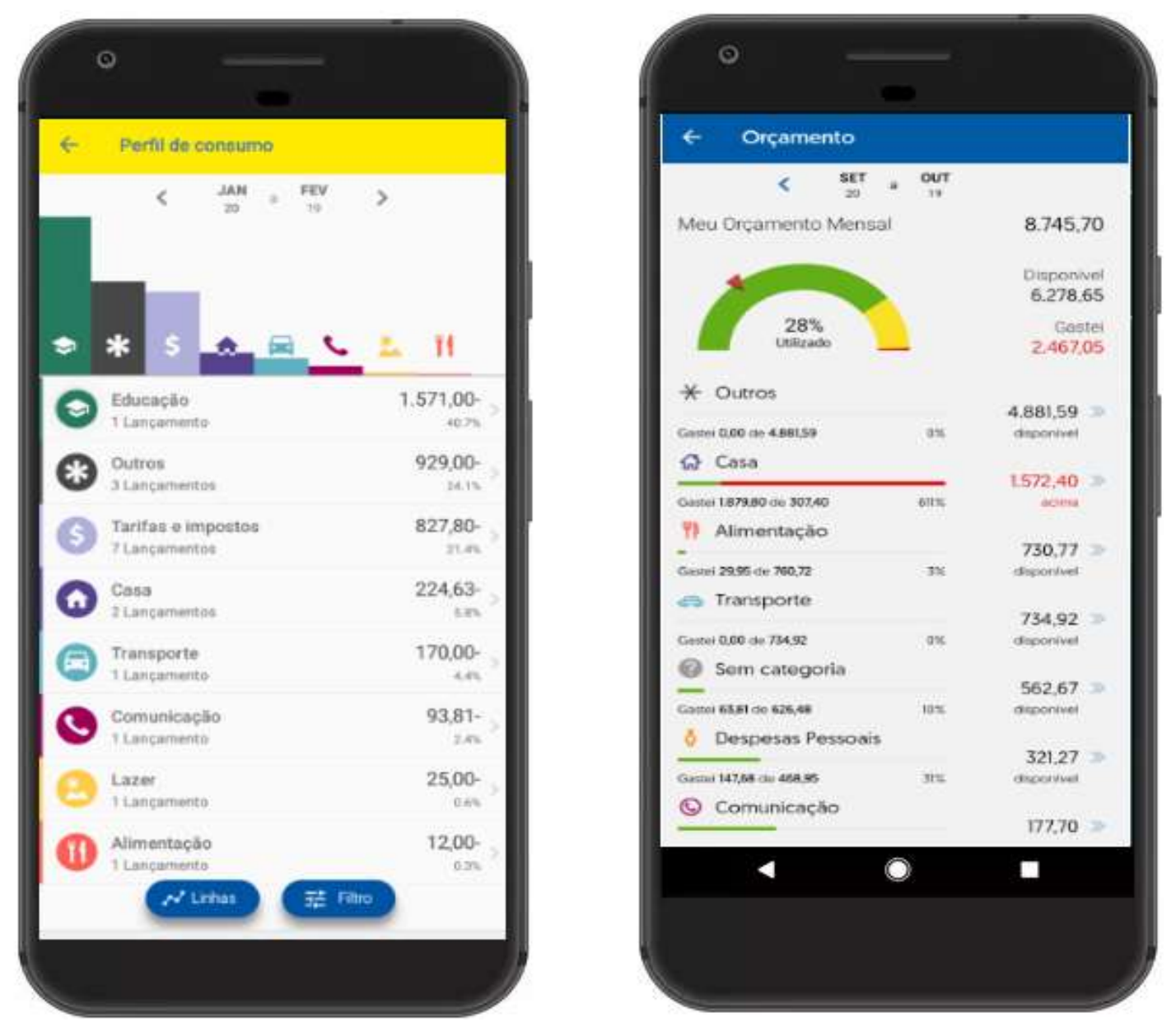

Fonte: modificada pelas autoras (2020).

NOTA: A tela à esquerda, correspondente à visualização de gastos, demonstra no quadrante superior um gráfico de barras ilustrando a proporção de despesas do usuário por categoria. Essas categorias estão caracterizadas através de pequenos ícones posicionados acima da barra do gráfico e são, por exemplo, uma casa, um carro, um telefone, etc. Abaixo deste gráfico de barras, demonstra-se um quadro que relaciona cada categoria de despesas com o valor gasto até o momento. A tela à direita ilustra um orçamento analítico, ou seja, dividido entre as categorias casa, alimentação, transporte, etc. Assim como, ilustra um comparativo entre orçado versus realizado total.

A partir do conhecimento do quanto gasta em cada categoria de despesa, disponibilizado pela ferramenta anterior, o usuário pode criar e acompanhar seu orçamento e, assim, também pode moldar suas decisões financeiras de acordo com o seu orçamento. 0 sucesso do seu plano dependerá do seu perfil. Porém, o que se quer afirmar aqui é que o orçamento é uma ferramenta útil para os agentes que buscam uma boa gestão de finanças pessoais.

Para elaborar e controlar o orçamento é necessário dividir os gastos em contas. Esta divisão da riqueza, conforme exposto na segunda seção, pode gerar dois vieses: (1) o agente pode tratar o dinheiro de cada conta de forma diferente, algumas formas mais descomprometidas que outras, sem pensar na riqueza como um total destas contas; (2) o agente pode transferir mentalmente gastos entre as contas por impulso, fazendo compras que ele mesmo não planejou; não existe um fiscal para este tipo de transferência, apenas o próprio agente. Por isso, elaborar um orçamento, utilizando um app, planilhas ou papel, auxilia o 
Decisões financeiras e o uso de aplicativos:

um estudo à luz da economia comportamental

indivíduo a se planejar, mas ainda deve existir cuidado quanto a decisões não desejadas relacionadas à Contabilidade Mental.

Já os alertas de orçamento insuficiente, também possuem relação com a Economia Comportamental. Isso pois, eles funcionam como nudges da saliência. Eles colocam em evidência uma informação importante e assim tentam orientar o usuário a diminuir seus gastos e a se manter dentro do que ele próprio deseja. O app apenas auxilia o usuário a ter o conhecimento da atual situação, não existe uma trava que o obrigue a se manter no orçamento. A liberdade de não seguir as orientações é uma característica essencial ao nudge, e esta é preservada pelo app.

\subsection{ALERTAS DE VENCIMENTO DE PAGAMENTOS E O NUDGE}

O alerta de vencimento de pagamentos são notificações enviadas para lembrar o usuário da data de vencimento destes pagamentos. Para isso o usuário registra antecipadamente o pagamento em uma espécie de calendário de pagamentos. Abaixo, a Figura 2 exemplifica esta funcionalidade.

Os alertas de vencimento de pagamentos também podem ser classificados como nudges, pois orientam os agentes a efetuarem seus pagamentos em dia. Estes nudges são especialmente úteis para os indivíduos que, focados em alguma escassez, costumam esquecer os prazos dos pagamentos ou necessitam de tempo para descapitalizar alguma quantia. Porém, estes nudges também podem evocar a dor do pagamento, pois quanto mais os indivíduos lembram de um pagamento mais eles sentem a dor do pagamento e os apps enviam alertas de vencimento até mesmo para os pagamentos que utilizam a ferramenta de débito automático disponibilizada pelos bancos. $\mathrm{O}$ indivíduo mais hedonista pode silenciar esta função. Já para os que preferem lembrar os pagamentos, mesmo que isso gere um desconforto, os alertas podem ser úteis.

\subsection{METAS DE POUPANÇA E A CONTABILIDADE MENTAL}

Nesta ferramenta o usuário registra um valor que gostaria de poupar em um período, geralmente semestral ou anual. Então, o app disponibiliza uma visualização fácil da meta de poupança versus o total poupado até o momento presente, conforme exemplo a ser ilustrado na Figura 2.

A meta de poupança pode ser uma das contas da Contabilidade Mental. Neste caso, ela pode ser benéfica, pois a criação de uma conta mental chamada "poupança" pode incentivar o indivíduo a poupar mais ao motivar a definição de metas concretas e atingíveis e devido à lembrança desse objetivo pré-estabelecido. (FRY et al., 2008). 
Figura 2 - Alertas de vencimento de pagamentos e metas de poupança
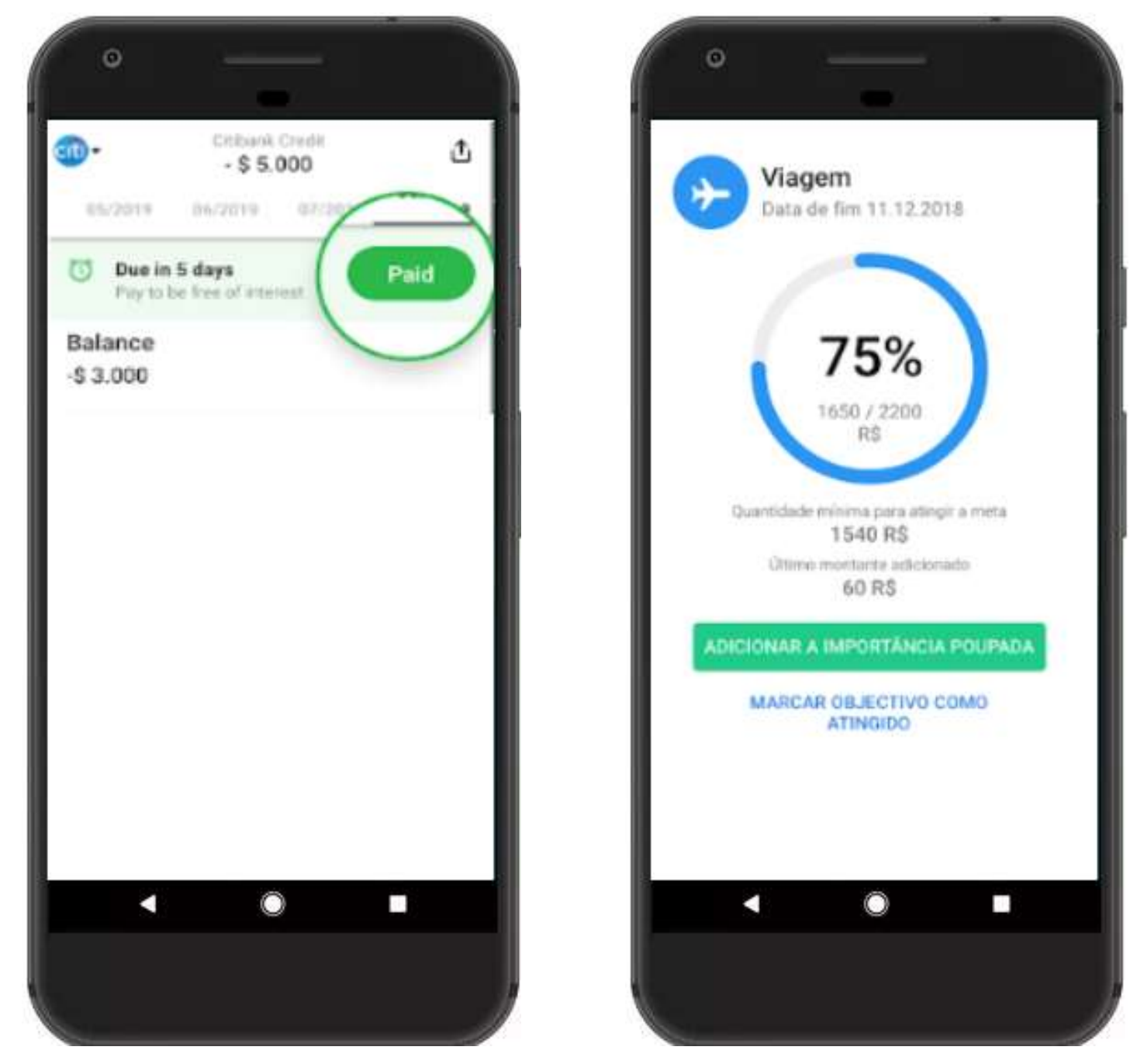

Fonte: modificada pelas autoras (2020).

Nota: A tela à esquerda demonstra o alerta do app sobre um pagamento cujo vencimento será em cinco dias. A tela à direita ilustra uma meta de poupança, cujo objetivo é uma viagem. Esta contém o valor total da meta, o valor poupado até o momento e o saldo.

\subsection{ESPECIFICAÇÃO DE EMOÇÃO RELACIONADA ÀS DESPESAS E À DOR DO PAGAMENTO}

Esta é uma ferramenta para o usuário classificar manualmente as despesas de um período, geralmente semanal, de acordo com o sentimento que a despesa the proporciona. A escala de emoções pode ser, por exemplo: não gosto, neutro e gosto. Ou ainda através de ícones como no exemplo acima na Figura 3. No final do período, o app calcula uma média das emoções e informa o usuário.

Esta ferramenta chama a atenção não apenas para o conhecimento dos gastos semanais e sua categorização, mas também para as emoções que os gastos proporcionam. Na linguagem da Economia Comportamental esta revisão de gastos versus sentimentos lembrará o usuário dos pagamentos da última semana e isso pode guia-lo a gastar naquilo que mais gera satisfação. Dar uma nota ruim a determinada despesa, pode fazer com que o usuário repense quando for gastar novamente com despesa semelhante. De outra forma, a lembrança de um pagamento que o usuário classificou como "gosto", por exemplo de um jantar com sua família, 
Decisões financeiras e o uso de aplicativos:

um estudo à luz da economia comportamental

pode fazê-lo decidir gastar mais com este tipo de evento. Assim, a categorização das despesas, de acordo com as emoções sentidas, pode orientar os agentes em suas decisões financeiras futuras.

Figura 3 - Emoções versus despesas
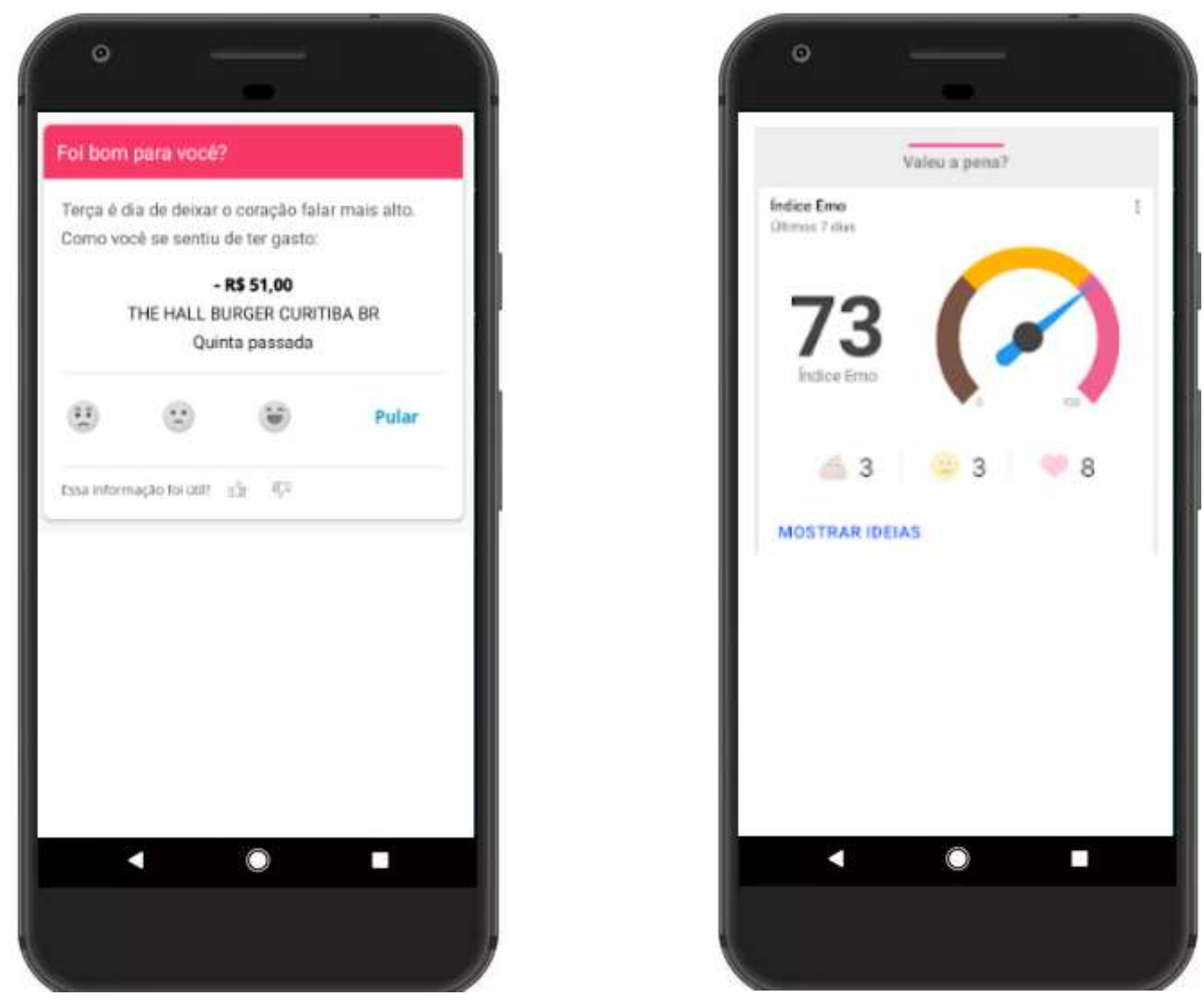

FONTE: modificada pelas autoras (2020).

NOTA: A tela à esquerda demonstra a classificação de uma despesa segundo a emoção causada por ela. A classificação das emoções é feita através dos ícones que demonstram rostos: triste, neutro e feliz. A tela à direita traz o resultado da classificação das despesas e toda a semana através de um índice de 0 a 100, também representado por cores e ícones.

\section{DISCUSSÃO}

A Economia Comportamental tem analisado os desafios em torno das decisões em finanças pessoais e chamado a atenção para a maneira como características cognitivas, emoções e a situação de escassez influenciam a gestão financeira. A utilização destas abordagens, usual no marketing, pode fundamentar o desenho de nudges para aplicativos de celular com grande possibilidade de auxiliar os indivíduos em suas decisões.

A análise desenvolvida identificou que as ferramentas oferecidas pelos apps de gestão financeira estão utilizando insights, deliberadamente ou não, relacionados à Economia Comportamental e que estas podem ser reconhecidas como nudges. As funcionalidades presentes em todos os apps da amostra foram a visualização de gastos categorizados e elaboração e acompanhamento do orçamento cujos efeitos sobre a decisão podem ser relacionados à saliência e à contabilidade mental. Outras funcionalidades só foram detectadas em alguns aplicativos como alertas de vencimento de pagamentos (6 apps), metas $e$ 
acompanhamento de poupança (3 apps) e categorização de gastos em escalas emocionais (2 apps). Nestes casos, há influência da lembrança de datas e metas, muito relevantes em situações de escassez, e das emoções, que podem guiar a decisão para resultados mais satisfatórios.

\section{CONSIDERAÇÕES FINAIS}

Os apps de gestão financeira podem trazer comodidade e praticidade. Os agentes poderiam criar as mesmas funcionalidades oferecidas por esses apps através de papel, planilhas, cronogramas, calendários etc. Mas, esses apps disponibilizam todas estas ferramentas juntas, ao alcance do usuário e seu uso pode ser bastante amigável. Por isso, os apps podem oferecer vantagens em comparação a outras formas de organizar as finanças pessoais.

As empresas têm se beneficiado da tecnologia para incentivar os agentes a comprar e a pagar. São exemplos os aplicativos de lojas para comprar direto da China, as "carteiras digitais" para pagar apenas tirando uma foto do $Q R$ Code e as lojas virtuais de livros que oferecem para os clientes cadastrados a funcionalidade de comprar apenas com um clique. A análise desenvolvida mostrou que as teorias e ferramentas utilizadas pelo marketing para orientar os agentes a comprar não são utilizadas, com a mesma intensidade, para orientá-los a poupar, por exemplo. Pode-se afirmar que os apps de gestão financeira apresentam uma postura um pouco passiva, comparada à postura "hiperativa" do marketing.

Eles poderiam explorar teorias inovadoras, como a Economia Comportamental, para a pesquisa de potenciais ferramentas que podem agregar valor aos usuários. Alguns trabalhos têm apontado influência promissora dessas ferramentas na melhoria da gestão de finanças pessoais (tais como Financial Advice Working Group, 2017; Wijland, Hansen e Gardezi, 2016 e Stockinger et al., 2015), mas ainda há carência de estudos que analisem como ocorre a influência sobre a decisão financeira dessas funcionalidades e quais as ferramentas mais eficientes. Este artigo procurou auxiliar nessa lacuna.

Este trabalho apresentou diversas influências psicológicas e contextual sobre as decisões financeiras. Muitos insights podem ser obtidos como ferramenta para o enfrentamento dos desafios da gestão das finanças pessoais. O aprofundamento deste tema pode, inclusive, possibilitar a produção de ferramentas personalizadas. Há grupos mais ou menos propensos a essas influências e a tecnologia já é capaz de incorporar em seus algoritmos quais ferramentas alcançam sucesso com determinada pessoa. Por exemplo, a situação de escassez é sentida por um grupo e não por todos ou a dificuldade em administrar gastos em diversos meios de pagamentos pode ser sentida apenas por uma parte dos indivíduos. Sendo assim, os aplicativos poderiam, primeiramente, fazer poucas perguntas que identificassem o perfil do usuário e o agrupasse conforme este perfil. A partir dessa identificação e do próprio uso do aplicativo, ele personalizaria para estes grupos de usuários alguns nudges que fariam diferença para este perfil.

Após esta pesquisa, algumas sugestões que envolvem os insigths de Economia Comportamental foram extraídas da literatura. (i) Os apps de gestão financeira podem explorar os custos de oportunidade e o viés da relatividade. O usuário poderia configurar que gosta de férias nas Bahamas e sapatos. Então, quando o usuário ficasse tentado a comprar algo diferente do planejado ou incomum, ele poderia usar o app para comparar o valor deste novo item ao valor dos itens que ele gosta ou está acostumado a adquirir. Isto é, o aplicativo responderia: "Esse novo item corresponde a meio dia nas Bahamas e dois pares de sapatos". Ou medindo em tempo de trabalho: "Esse novo item corresponde a três dias de trabalho". (ii) 
Decisões financeiras e o uso de aplicativos:

um estudo à luz da economia comportamental

A dor do pagamento pode ser útil a um perfil específico de usuários. Isso pois, a possibilidade de senti-la pode abortar gastos com o intuito de evitar o desconforto da dor. Então, os apps podem sugerir a determinado grupo de usuários o pagamento em dinheiro ou à vista. (iii) Pode-se aumentar os índices de poupança dos usuários de app ao lembrá-los para o que estão poupando através de uma foto ou imagem. Isso pois, a foto pode conectá-los emocionalmente com este gasto futuro. (iv) Pode-se incrementar os alertas de vencimentos de pagamentos, através do nudge de enquadramento, adicionando o valor da multa e dos juros caso o pagamento não seja efetuado. Devido a aversão a perda, o indivíduo pode se sentir mais incentivado a realizar o pagamento em dia.

Por fim, as notificações enviadas pelo app podem ser mais exploradas, isso pois a grande maioria delas traz apenas lembretes para imputar a movimentação financeira manualmente. As notificações podem ser mais criativas, trazer informação inteligente, pequenos gráficos e relatórios semanais, sem exceder a quantidade de informação que pode ser absorvida periodicamente pelo usuário. Assim, a teoria da Economia Comportamental pode trazer bastante contribuição para estas notificações criativas, assim como, para criação de ferramentas úteis aos apps que ultrapassam este artigo.

\section{REFERÊNCIAS}

ARIELY, D.; KREISLER, J. A psicologia do dinheiro. Rio de Janeiro: Sextante, 2019.

ARIELY, D.; SHAMPAN'ER, K. How small is zero price? The true value of free products. FRB of Boston working paper, n. 06-16, 2006. DOI: http://dx.doi.org/10.2139/ssrn.951742.

ASSOCIAÇÃO BRASILEIRA DAS ENTIDADES DOS MERCADOS FINANCEIROS E DE CAPITAIS (ANBIMA). Raio-X do investidor brasileiro. Rio de Janeiro, 2019. Disponível em: https://www.anbima.com.br/pt_br/especial/raio-x-do-investidor-2019.htm. Acesso em: 01 ago. 2019.

ATKINSON, A.; MESSY, F. Measuring financial literacy: results of the OECD / International Network on Financial Education (INFE), pilot study, OECD working papers on finance, insurance and private pensions, n. 15, 2012. DOI: http://dx.doi.org/10.1787/5k9csfs90fr4en.

BENARTZI, S.; THALER, R. Heuristics and biases in retirement savings behavior. Journal of Economic Perspectives, Pittsburgh, v. 21, n. 3, p. 81-104, 2007. DOI: 10.1257/jep.21.3.81.

BRUNE, L.; GINÉ, X.; GOLDBERG, J.; YANG, D. Commitments to save: a field experiment in rural Malawi. Policy Research Working Paper, The World Bank, 2011. DOI: https://doi.org/10.1596/1813-9450-5748.

CROSGRAVE, L. Christmas clubs. The Quarterly Journal of Economics, Cambridge, v. 41, n. 4, p. 732-739, 1927. DOI: https://doi.org/10.2307/1884889.

DELOITTE. Pesquisa Febraban de tecnologia bancária 2020. Mobile banking é canal preferido dos brasileiros para pagamento de contas e transferências bancárias, 2019. Disponível em: https://portal.febraban.org.br/noticia/3301/pt-br/. Acesso em: 02 nov. 2020. 
FINANCIAL ADVICE WORKING GROUP. Rules of thumb and nudges: improving the financial well-being of UK consumers - Prepared for HM Treasury and the Financial Conduct Authority, 2017. Disponível em: https://www.fca.org.uk/publication/research/fawg-rules-of-thumbnudges.pdf. Acesso em: 18 nov. 2020.

FRY, T.; MIHAJILO, S.; RUSSEL, R.; BROOKS, R. The factors influencing saving in a matched savings program: goals, knowledge of payment instruments, and other behavior. Journal of Family and Economic Issues, North Andover, v. 29, n. 2, p. 234-250, 2008. DOI: https://doi.org/10.1007/s10834-008-9106-y.

HAUSMAN, D.; WELSH, B. Debate: to nudge or not to nudge? The Journal of Political Philosophy, Oxford, v. 18, n. 1, p. 123-136, 2010. DOI: https://doi.org/10.1111/j.14679760.2009.00351.x.

HERSHFIELD, H; GOLDSTEIN, D; SHARPE, W; FOX, J; YEYKELIS, L; CARSTENSEN, L; BAILENSON, J. Increasing saving behavior through age-progressed renderings of the future self. Journal of Marketing Research, Chicago, v. 48, p. 23- 27, 2011. DOI: 10.1509/jmkr.48.SPL.S23.

HERSHFIELD, H.; WIMMER, E.; KNUTSON, B. Saving for the future self: neural measures of future self-continuity predict temporal discounting. Social Cognitive and Affective Neuroscience, Oxford, v. 4, n.1, 2009. DOI: 10.1093/scan/nsn042.

KAHNEMAN, D.; TVERSKY, A. Prospect theory: an analysis of decision under risk? Econometrica, Chicago, v. 47, n. 2, p. 263-291, 1979. DOI: https://doi.org/10.2307/1914185.

KEYS, A.; BROZEK, J.; HENSCHEL, A.; MICKELSON, O.; TAYLOR, H. The biology of human starvation, v. 1 e v. 2. Oxford: University of Minnesota Press, 1950.

LOEWENSTEIN, G.; BRYCE, C.; HANGMANN, D.; RAJPAL, S. Warning: you are about to be nudged. Behavioral Science \& Policy, Durham, v. 1, n. 1, p. 35-42, 2015. DOI: http://dx.doi.org/10.2139/ssrn.2417383.

LYNCH, J. Introduction to the Journal of Marketing Research special interdisciplinary issue on consumer financial decision making. Journal of Marketing Research, Chicago, v. 48, 2011. p. Si-Sv DOI: 10.1509/jmkr.48.SPL.Siv.

MANI, A.; MULLAINATHAN, S.; SHAFIR, E.; ZHAO, J. Poverty impedes cognitive function. Science, Nova York, v. 341, n. 6149, p. 976-980, 2013. DOI: 10.1126/science.1238041.

MAZAR, N.; PLASSMANN, H.; ROBITAILLE, N., LINDNER, A. Pain of paying? - a metaphor gone literal: evidence from neural and behavioral science, Documento de trabalho, Rotman School of Management, INSEAD, Toronto, n. 2.901.808, 2016. DOI: 10.2139/ssrn.2901808.

MEIER, S.; SPRENGER, C. D. Present-biased preferences and credit card borrowing. American Economic Journal: Applied Economics, Nashville, v. 2, n. 1, p. 193-210, 2010. DOI: 10.1257/app.2.1.193. 
Decisões financeiras e o uso de aplicativos: um estudo à luz da economia comportamental

MIRSCH, T.; LEHRER, C.; JUNG, R. Digital nudging: altering user behavior in digital

Environments. In: $13^{\text {th }}$ International Conference on Wirtschaftsinformatik, 2017, St. Gallen, Suíça. Disponível em: https://wi2017.ch/images/wi2017-0370.pdf. Acesso em: 21 jan. 2020.

MULLAINATHAN, S.; SHAFIR, E. Escassez: uma nova forma de pensar a falta de recursos na vida das pessoas e nas organizações. Rio de Janeiro: Best Business, 2016.

MULLAINATHAN, S.; THALER, R. Behavioral Economics. In: Smelser, N.J.; and Paul B. Baltes, P. B. (Org.) International Encyclopedia of the Social \& Behavioral Sciences, v. 20, p. 1094-1100. Oxford, Oxford University Press. 2001. DOI: http://dx.doi.org/10.1016/B0-08-0430767/02247-6.

ORGANISATION FOR ECONOMIC CO-OPERATION AND DEVELOPMENT - OECD. Recommendation on principles and good practices for financial education and awareness, 2005. Disponível em: http://www.oecd.org/finance/financial-education/35108560.pdf. Acesso em: 13 fev. 2020.

OZDEMIR, S. Digital nudges and dark patterns: the angels and the archfiends of digital communication. Digital Scholarship in the Humanities, Oxford, v. 35, n. 2, p. $417-518$, 2020. DOI: https://doi.org/10.1093/llc/fqz014.

PRELEC, D.; LOEWENSTEIN, G. The red and the black: mental accounting of savings and debt. Marketing Science, Catonsville, v. 17, n. 1, p. 4-28. 1998. DOI: http://dx.doi.org/10.1287/mksc.17.1.4.

SCHNEIDER, C.; WEINMANN, M.; BROCKE, J.V. Digital nudging: guiding online user choices through interface design. Communications of the ACM, Nova York, v. 61, n. 7, p. 67-73, 2018. DOI: https://doi.org/10.1145/3213765.

SCHUBERT, C. Green nudges: Do they work? Are they ethical? Ecological Economics, v. 132, i. C, p. 329-342, 2017. DOI: https://doi.org/10.1016/j.ecolecon.2016.11.009.

SCHUBERT, C. On the ethics of public nudging: Autonomy and agency. MAGKS Papers on Economics, Marburg, n. 33, 2015. Disponível em: https://www.unimarburg.de/fb02/makro/forschung/magkspapers/paper_2015/33-2015_schubert.pdf. Acesso em: 10 jan. 2020.

SHAH, A; MULLAINATHAN, S; SHAFIR, E. Some consequences of having too little. Science, Nova York, v. 338, n. 6107, p. 682-685, 2012. DOI: 10.1126/science.1222426.

SIMON, H. Theories of decision-making in economics and behavioral science. American Economic Review, Pittsburgh, v. 49, n. 3, 1959. DOI: https://doi.org/10.1007/978-1-34900210-8_1. 
SIMONSON, I. Choice based on reasons: the case of attraction and compromise effects. Journal of Consumer Research, Oxford, v. 16, n. 2, p. 158-174, 1989. DOI: https://doi.org/10.1086/209205.

SOMAN, D. Effects of payment mechanism on spending behavior: the role of rehearsal and immediacy of payments. Journal of Consumer Research, Oxford, v. 27, p. 460 - 474, 2001. DOI: $10.1086 / 319621$.

STATCOUNTER. Mobile operating system market share worldwide. Disponível em: https://gs.statcounter.com/os-market-share/mobile/worldwide. Acesso em: 01 fev. 2020.

STOCKINGER, T.; KOELLE, M.; LINDEMANN, P.; KRANZ, M. DIEWALD, S. MÖLLER, A. ROALTE, L. Towards leveraging Behavioral Economics in mobile application design. In: REINERS, T.; WOODS, L. (Org.) Gamification in Education and Business. Springer International Publishing, 2015. DOI: https://doi.org/10.1007/978-3-319-10208-5_6.

THALER, R. Mental accounting and consumer choice. Marketing Science, Catonsville, v. 4, n 3, 1985. DOI: https://doi.org/10.1287/mksc.4.3.199.

THALER, R; SUNSTEIN, C. Nudge: o empurrão para a escolha certa. Rio de Janeiro: Elsevier, 2009.

TVERSKY, A; KAHNEMAN, D. Judgment under uncertainty: heuristics and biases. Science, Nova York, v. 185, n. 4157, p. 1124-1131, 1974. DOI: 10.1126/science.185.4157.1124.

ZELLERMAYER, O. The pain of paying. 1996. Tese. Department of Social and Decision Sciences, Carnegie Mellon University, Pittsburgh, 1996.

WIJLAND, R.; HANSEN, P.; GARDEZI, F. Mobile nudging: youth engagement with banking apps. Journal of Financial Services Marketing, v. 21, n. 1, p. 51-63, 2016. DOI: https://doi.org/10.1057/fsm.2016.1. 